\title{
Diplomatic Persuasion: An Under-Investigated Process
}

\author{
Pauline L. Kerr \\ Australian National University, Canberra, ACT, Australia \\ pauline.kerr@anu.edu.au
}

Received: 26 August 2009; revised: 1 December 2009; accepted: 23 December 2009

\begin{abstract}
Summary
The under-investigation in diplomatic studies of processes of persuasion in explaining diplomatic outcomes needs to be addressed in the interests of better scholarly explanations and diplomatic practice. Although such processes are implicit in nearly all concepts and practice of diplomacy, neither scholars nor practitioners explicitly investigate them. Yet other related fields of study and disciplines examine persuasion and demonstrate its explanatory value. Drawing on this literature, but also bearing in mind the nature of outcomes that diplomatic studies seeks to understand, this article offers a model of processes of persuasion and illustrates its potential for explaining a 2003 peace process negotiation in the Solomon Islands.
\end{abstract}

\section{Keywords}

Diplomatic studies and practice, processes of persuasion, argumentation and reasoning, coercive argumentation, coercive framing, coercive rhetoric, non-verbal coercive and non-coercive signals, negotiations

\section{Introduction: A Missing Investigation}

Most scholars and practitioners of diplomacy would agree that persuasion - the process of arguing and reasoning - is central to understanding their subject matter and profession, respectively. ${ }^{1}$ Even in the current debate about what constitutes the essence of contemporary diplomacy, which is often cast as a contest

1) Diplomacy scholars at the focus of this article are those who conceptualize and research the practices of diplomacy and offer explicit arguments about what is, and ought to be, the focus of study and practice of diplomacy. By contrast, many other scholars' works implicitly inform diplomacy, but they are by-products of investigations into other issues. For example, the article will show that although constructivist scholars examine persuasive processes that inform the study of diplomacy, that is not their intent. Interestingly, these scholars often use empirical examples of diplomatic practice to make their argument about another issue, for example the socializing role of institutions. Reference to the term 'diplomatic studies' is used to denote work that is aimed at conceptual elaborations and research that aims to advance the study and practice of diplomacy. Another point of clarification is that this article emphasizes processes of persuasion, and not necessarily an outcome where these processes are successful. Although the article uses the term 'persuasion', it refers to processes as explanatory variables, albeit variables that are constituted by other processes. In social science terms, processes of persuasion are independent variables. 
between the elements of classical and 'new' diplomacy, persuasion is a shared albeit unspoken - concept. $^{2}$ The classical notion of diplomacy as involving state-based diplomats from foreign ministries communicating and representing their state-centric interests and values to officials and publics in other states is surely an exercise in persuasion of different degrees. ${ }^{3}$ Likewise, understandings of new diplomacy - as involving a range of diplomatic actors, not just from foreign ministries and the international sections of other governmental departments but also non-state actors, many of whom are focused on finding collective governance mechanisms for a range of global issues - involve persuasion. Networked or catalytic diplomacy, another feature of new diplomacy, must also include processes of persuasion to build and manage networks among a variety of actors, such as between governments and their domestic publics, between different government departments and between these players and their state and non-state equivalents across the globe. ${ }^{4}$ The vast literature on public diplomacy, including 'new' public diplomacy, is another area where processes of persuasion are used by one state to influence the thinking of foreign publics in another state. ${ }^{5}$ The

2) Key studies of new diplomacy include: A.F. Cooper and Brian Hocking, 'Governments and NonGovernment Organizations and the Recalibration of Diplomacy', Global Society, vol. 14, no. 3, 2000, pp. 361-376; Brian Hocking, Foreign Ministries: Change and Adaptation (London: Macmillan, 1999); Brian Hocking, 'Privatizing Diplomacy?', International Studies Perspectives, no. 5, 2004, pp. 147-152; John Hoffman, 'Reconstructing Diplomacy', British Journal of Politics and International Relations, vol. 5 , no. 4, 2003, pp. 525-542; Jan Melissen (ed.), Innovation in Diplomatic Practice (New York: Macmillan, 1999); David D. Newson, 'The New Diplomatic Agenda: Are Governments Ready?', International Affairs, vol. 89, no. 1, 1989, pp. 29-41; Luc Reychler, 'Beyond Traditional Diplomacy' (Leicester: Diplomatic Studies Programme, University of Leicester, 2003); Shaun Riordan, The New Diplomacy (Cambridge: Polity Press, 2003); Sasson Sofer, 'Old and New Diplomacy: A Debate Revisited', Review of International Studies, no. 14, pp. 1-12; and Paul Sharp, 'For Diplomacy: Representation and Study of International Relations', International Studies Review, vol. 1, no. 1, 1994, pp. 33-57. A useful discussion of the scope of studies on diplomacy is Stuart Murray, 'Consolidating the Gains Made in Diplomacy Studies: A Taxonomy', International Studies Perspectives, no. 9, 2008, pp. 22-39.

3) Key writings on classical diplomacy include: G.R. Berridge, Diplomatic Theory from Machiavelli to Kissinger (London: Palgrave, 2001); Hedley Bull, The Anarchical Society: A Study of Order in World Politics (New York: Palgrave, 1977); Henry A. Kissinger, Diplomacy (New York: Simon \& Schuster, 1994); Harold Nicolson, The Evolution of the Diplomatic Method (New York: Macmillan, 1953); Harold Nicolson, Diplomacy (Oxford: Oxford University Press, 1953); Adam Watson, Diplomacy: The Dialogue Between States (London: Eyre Methuen, 1982); A. de Wicquefort, The Ambassador and His Functions (translated by J. Digby in 1716) (Leicester: Centre for the Study of Diplomacy, University of Leicester, 1997); and Martin Wight and Herbert Butterfield, Diplomatic Investigations (Cambridge MA: Harvard University Press, 1966).

4) Brian Hocking, Localizing Foreign Policy: Non-Central Governments and Multilayered Diplomacy (London: Palgrave, 1993); and Brian Hocking, 'Catalytic Diplomacy: Beyond "Newness and Decline"', in Jan Melissen (ed.), Innovation in Diplomatic Practice (New York: Macmillan, 1999), pp. 21-42. Also see the references in footnote 2.

5) Jan Melissen (ed.), The New Public Diplomacy: Soft Power in International Relations (London: Palgrave Macmillan, 2005); Geoffrey Cowan and Amelia Arsenault, 'Moving from Monologue to Dialogue to Collaboration: The Three Layers of Public Diplomacy', in Geoffrey Cowan and Nicholas J. Cull (eds.), Public Diplomacy in a Changing World: The Annals of the American Academy of Political and Social Science, vol. 616, March 2008, pp. 10-30; Daryl Copeland and Evan H. Potter, 'Public Diplomacy in Conflict 
explicit recognition that diplomacy involves advocacy is further evidence that persuasion takes centre stage. ${ }^{6}$ Finally, if - as many scholars and practitioners claim - negotiation is the essential activity of diplomacy and if negotiation is centred on persuasion through argument and reasoning as well as bargaining, then whatever the differences between classical and new diplomacy are, persuasion is also an essential element. Indeed, it is difficult to think of any aspect of diplomacy without bringing persuasion to mind.

It is surprising, then, that processes of persuasion are under-investigated by both scholars and practitioners of diplomacy. Accounts of classical diplomacy that emphasize communication provide conceptual and empirical confirmation of its importance but rarely investigate the processes of persuasion that are surely inherent in communication. Elaborations of new diplomacy similarly do not explore this level of analysis. ${ }^{7}$ Likewise, theorists and trainers of negotiation who, respectively, focus on illuminating concepts and processes (such as log-rolling and concession-making) and teaching these tactics and strategies — do not study the processes of persuasion or teach a skill-set that involves these processes. Rather, negotiation outcomes are usually explained in terms of structures such as power asymmetries, usually on the part of major players, or in terms of processes such as bargaining. ${ }^{8}$ Similarly, outcomes of diplomatic interactions are usually described as the result of applying certain diplomatic tools or instruments, such as coercive diplomacy, summit diplomacy, multilateral diplomacy, leverage, incentives and sanctions. Practitioners - who are undeniably masters of processes of persuasion and no doubt recognize themselves as such - occasionally use the term but rarely isolate and reflect on it in an explicit and systematic way that would help them to articulate their tacit know-how to others. ${ }^{9}$ From a

Zones: Military Information Operations Meet Political Counter-Insurgency', The Hague Journal of Diplomacy, vol. 3, no. 3, 2008, pp. 277-297; Kathy R. Fitzpatrick, 'Advancing the New Diplomacy: A Public Relations Perspective', The Hague Journal of Diplomacy, vol. 2, no. 3, 2007, pp. 187-211; and Geoffrey Wiseman, "Polylateralism” and New Modes of Global Dialogue', in Christer Jönsson and Richard Langhorne (eds.), Problems and Issues in Contemporary Diplomacy, vol. 3 (London: Sage, 2004), pp. 36-57.

๑) Charles W. Freeman, Arts of Power: Statecraft and Diplomacy (Washington DC: US Institute of Peace Press, 1997), pp. 115-120.

7) For example, in their article arguing that communication is an essential aspect of diplomacy, Jönsson and Hall emphasize that social communication, including diplomatic communication, involves the transmission of messages to which certain meanings are attached', but they do not investigate the processes through which such messages might persuade the receiver. See Christer Jönsson and Martin Hall, 'Communication: An Aspect of Diplomacy', International Studies Perspectives, vol. 4, no. 2, 2003, pp. $195-210$ at p. 201.

8) Although some negotiation theorists examine processes, such as emotions of anger, and many examine tactics, such as alternating cooperation and competition in negotiation, few (apart from the political psychology scholars who study negotiation) investigate the processes of argumentation, reasoning, framing and coercion.

9) This observation is made on the basis of conversations with several diplomats, some of whom teach young diplomats. 
disciplinary standpoint, the under-investigation of persuasion is also surprising, because related fields do study these processes, even diplomacy's partner discipline: international relations (IR). One final thought is that processes of persuasion are perhaps so obvious that they are taken for granted, or examined under different labels. If, for argument's sake, diplomatic communication and negotiation are self-evidently about persuasion but not labelled as such, then there is little to learn and we can substitute communication and negotiation for persuasion and carry on as before.

This article, however, argues that there is intellectual and practical value in identifying and explicitly investigating the processes of persuasion within diplomatic studies, just as other areas study them. Important insights into diplomacy are missed by taking processes of persuasion for granted, ignoring them or assuming that they can be labelled as synonyms for commonly used terms. We miss seeing that there is an important level of analysis that is centred on processes and that will more comprehensively and therefore better explain diplomatic outcomes and the nature of diplomatic agency. We gain important practical insights by making such processes explicit and the focus of research. For example, the knowledge that processes explain outcomes is an incentive for practitioners to make their tacit knowledge explicit and transmit it to others. In short, research projects that investigate processes of persuasion have the potential to advance the study and practice of diplomacy. Such advances are crucial in these contemporary times when collective action appears to be the only approach to common global problems such as climate change and pandemics, and when - in an economically globalized world - the use of force is not only irrelevant for managing such issues but is a less-effective instrument of power. Enhancing diplomatic approaches is even timelier today when leaders from the United States, Europe and China are turning to diplomatic management and solutions and looking for new diplomatic approaches to advance their agendas. As US Secretary of State Hillary Clinton said in her confirmation testimony on 4 May 2009, 'diplomacy will be the vanguard of [US] foreign policy'. ${ }^{10}$

This article's contribution to investigating persuasion within diplomatic studies starts the journey towards developing a diplomatic studies model of persuasion to help explain diplomatic outcomes. Three main arguments are: first, such a model can partly be built from existing models in other literature, in particular IR constructivist scholarship and political psychology. Although there are similarities between these literatures and diplomatic studies, there are also differences. Second, a diplomatic studies model therefore needs to accommodate: 1) the greater variation that characterizes such studies - that is, the broader

10) US Department of State, available online at http:www.state.gov/secretary/rm/2009a/01/115196. $\mathrm{htm}$. See also US Vice President Joe Biden's speech at the 45th Munich Conference on Security, 7 February 2009, available online at http://www.whitehouse.gov/the_press_office/Remarks by Vice President Biden at 45th Munich Conference, accessed 4 June 2009. 
range of political outcomes that have to be explained, the wider the range of actors involved; 2) the variation in persuasive processes, particularly those that are coercive or political or power-based and are therefore different to the mainstream constructivist model $;{ }^{11}$ and finally, the model needs to incorporate the multi-level and multi-faceted conditions under which diplomatic persuasion operates. The third argument is that a diplomatic studies model also needs to reconceptualize the constructivist understanding of persuasion and see it as a process that includes coercive argumentation, comprising inter alia coercive framing and coercive rhetoric; ${ }^{12}$ and likewise, to incorporate conditions that are political and coercive, including non-verbal signals that are created specifically to support the argumentation. A diplomatic studies model will better explain most diplomatic outcomes, whereas the constructivist model will continue to explain those rare episodes where coercive argumentation is not a factor. The article's final contribution is to illustrate the usefulness of the model for explaining a diplomatic peace negotiation.

The first part of the article provides a brief review of how persuasion is studied in constructivism and political psychology, before examining the strengths and shortcomings of these studies from a diplomatic studies perspective. Three models of persuasion are constructed from this analysis: constructivist; political psychology; and diplomatic. The second part of the article applies the three models empirically to establish their respective value in explaining the political outcome of a 2003 peace agreement in the Solomon Islands, which - typical of 'new' diplomacy — involved a range of diplomatic actors in an intra-state settlement.

\section{Studies of Processes of Persuasion}

The concept of persuasion has been explicitly identified and studied by scholars from different disciplines for many years. Scholars in international relations,

11) It is common knowledge that there are many types of constructivists. The focus here is on those who reject or are ambiguous about the role of coercion, politics or power in processes of persuasion. One of the few scholars who engages more directly with these issues is Neta A. Crawford in her book Argument and Change in World Politics (Cambridge: Cambridge University Press, 2002).

12) There are many definitions of coercion. The Concise Oxford English Dictionary defines the verb 'to coerce' as 'to persuade (an unwilling person) to do something by using force or threats' (note that the definition does not specify the nature of the threats - for example, whether or not they are explicit or implicit, material or verbal.) The noun 'coercion' is derived from the above definition and has the added connotation of 'restraint'; see Catherine Soanes and Angus Stevenson (eds.), Concise Oxford English Dictionary (Oxford: Oxford University Press, 2006), p. 277. According to self-labelled 'coercive constructivists' Krebs and Jackson, who distinguish themselves from their 'liberal constructivist' colleagues, 'the defining feature of coercion is (non-consensual) compliance'; see Ronald R. Krebs and Patrick Thaddeus Jackson, 'Twisting Tongues and Twisting Arms: The Power of Political Rhetoric', European Journal of International Relations, vol. 13, no. 1, 2007, p. 58. In this article, coercion refers to implicit threats in the persuader's argumentation that the persuadee may be constrained in achieving their interests, that non-compliance may have negative consequences. The emphasis is therefore on coercive argumentation, which includes coercive framing and coercive rhetoric, as explained later. 
legal studies, political psychology, rhetoric studies, communications and media studies, business and management regularly publish books and articles on persuasion. In recent years several journals - for example, International Organization, Political Psychology, and Group Decision and Negotiation - have all published many articles on persuasion. The body of scholarship is expanding, the standard is generally high and in many instances the conceptual elaborations and research findings appear relevant to diplomatic studies, although this is rarely recognized or made explicit by the scholars themselves or scholars of diplomacy. Several articles show that it is possible to construct two models of persuasion - a constructivist international relations model and a political psychology model — and the models are discussed in terms of the three elements that constitute them: the types of political outcomes on which these articles focus; the processes of persuasion that typify each model; and the conditions under which these processes operate. The following section analyses the strengths and shortcomings of these models for developing a diplomatic studies model of persuasion.

\section{Outcomes and Processes of Persuasion}

The purpose of many scholarly works on persuasion is to investigate the concept's potential as a process to explain outcomes, in particular political outcomes that are understood in terms of change, continuity, or cocktails of both. The scholarly focus on processes is located within a long-standing debate that pits these types of explanatory factors against material or structural factors, ${ }^{13}$ although some scholars now consider the dichotomy to be somewhat artificial. ${ }^{14}$ Constructivist and political psychology studies provide some of the most insightful research on the role of processes of persuasion in explaining the particular outcomes that are the focus of their projects. Zürn and Checkel, constructivists in $\mathrm{IR}$, are interested in processes as causal mechanisms. Mechanisms, they suggest, 'clarify what happens between a cause and its effect, [...] how the former relates to the latter'. ${ }^{15}$ An example of a causal mechanism is, they argue, 'arguing and persuasion [...] that leads to a change in the interests or behaviour of the actors

13) In IR, structural realists argue that states pursue self-help and competition, manifested as material power in military and economic assets, because the international system is one of anarchy and structures of bipolarity, unipolarity or multipolarity.

14) In the IR literature, the distinction between processes and material factors as explanatory factors is part of a larger debate about the role of ideas and agency on the one hand, and material power balances repeated throughout history on the other. In its early stages, the debate cast agency and structure as alternative explanations, but over time, as it became evident that there were connections between the two, debate continued around other issues. For some constructivists, the connections suggested that agency and structures constituted each other. For others, processes were not just causal factors but also constituting factors that defined an actor's identity. For example, the socialization process of persuasion, according to some constructivists, constitutes the identity of many European institutions.

15) Michael Zürn and Jeffrey T. Checkel, 'Getting Socialized to Build Bridges: Constructivism and Rationalism, Europe and the Nation-State', International Organization, vol. 59, no. 4, fall 2005, p. 1048. 
concerned'. ${ }^{16}$ The change in interest, or the outcome, that constructivists wish to explain is socialization - that is, 'the internalization of new group norms through [processes of] persuasion and/or communicative action' ${ }^{17}$ Many constructivists examine the features of international institutions as triggering mechanisms for processes, such as persuasion, that can in turn lead to change, or new roles or interests. ${ }^{18}$

Like constructivists in IR, scholars of political psychology seek to explain the role of processes in explaining political outcomes. ${ }^{19}$ However, the latter focus on outcomes such as changes and continuities in citizens' and elites' political opinions. These scholars argue that the psychological processes of individuals or small groups are important for understanding outcomes: processes such as cognition or the way in which information is processed; the way an issue is framed (for example, using values or emotive factors such as danger); and personal attributes such as the trustworthiness of the message-sender. Many scholars of political psychology argue that these types of psychological factors are integral to persuasion.

\section{The Processes of Persuasion}

The constructivist and political psychology literature makes important contributions to analysing and conceptualizing the actual processes that — from their respective perspectives - constitute persuasion. Two of the many points made by constructivists are that: first, such processes are micro-processes, or, as Johnston argues, persuasion is a 'critical socialization micro-process', and that furthermore they are causal mechanisms; and second, that persuasion can be usefully conceptualized in two ways, as 'argumentative rationality' and 'argumentative persuasion'. ${ }^{20}$ Risse draws on Jurgen Habermaus' concept of communicative action to develop his concept of argumentative rationality. ${ }^{21}$ Risse defines argumentative rationality as a process that involves an 'ideal speech situation' or a 'logic of truth-seeking or arguing' through which actors try to figure out 'whether their assumptions about the world and about cause-and-effect relationships in the world are correct [...]; or whether norms of appropriate behaviour can be justified, and which norms apply under given circumstances'. ${ }^{22}$ The goal of argumentative rationality is 'to seek reasoned consensus' about a situation. ${ }^{23}$

\footnotetext{
16) Zürn and Checkel, 'Getting Socialized to Build Bridges', p. 1049.

17) Alaistair Iain Johnston, 'Conclusions and Extensions: Toward Mid-Range Theorizing and Beyond Europe', International Organization, vol. 59, no. 4, fall 2005, p. 1014.

18) Jeffrey T. Checkel, 'International Institutions and Socialization in Europe: Introduction and Framework', International Organization, vol. 59, no. 4, fall 2005, pp. 801-826.

19) For example, the journal Political Psychology regularly publishes material of this nature.

20) Johnston, 'Conclusions and Extensions', p. 1013.

21) Thomas Risse, “Let's Argue!”: Communicative Action in World Politics', International Organization, vol. 54, no. 1, winter 2000, pp. 1-39.
}

22) Risse, “Let's Argue!"', pp. 6-7.

23) Risse, “"Let’s Argue!”, p. 9. 
Importantly, argumentative rationality is a non-coercive process through which the better argument evolves and leads to reasoned consensus. To illustrate his point, Risse refers to diplomatic negotiations as a setting in which arguing aimed at consensus takes place, albeit that his objective is not to gain insights into diplomacy but rather, within the context of the rationalist-constructivist debate, to illustrate the importance of arguing/reasoning when differentiating between social interaction and strategic bargaining and rule-guided behaviour. ${ }^{24}$ Arguing, Risse claims, is important in the different stages of international negotiations: from the pre-negotiating phase when actors develop 'common knowledge' about the situation through arguing and then hopefully reach reasoned consensus; to the actual negotiation when both problem-solving and the associated distributive bargaining processes require arguing to agree on principles of fairness and justice that allow for distributive bargaining and an overall successful negotiation outcome. ${ }^{25}$ Risse's application of argumentative rationality to empirical cases suggests that the concept has explanatory value. He concludes, for example, that the successful outcome of international diplomatic negotiations between the United States and the former Soviet Union about ending the Cold War in Europe and settling international issues concerning German unification 'resulted from successful effort on both sides at arguing out the differences in a true dialogue of mutual persuasion'26 and that 'we cannot explain the cooperative outcome of these negotiations without acknowledging that argumentative rather than instrumental rationality prevailed during crucial phases. ${ }^{27}$

Whereas Risse refers to Habermaus, another constructivist - Checkel builds upon social psychology and communications research on persuasion and argumentation to develop a concept of 'argumentative persuasion'. ${ }^{28}$ Checkel defines argumentative persuasion as 'a social process of interaction that involves changing attitudes about cause and effect in the absence of overt coercion' and he defines persuasion as 'a process of convincing someone through argument and principled debate. ${ }^{29}$ Checkel distinguishes argumentative persuasion from manipulative persuasion, which he argues is 'asocial and lacking in interaction, often concerned with political elites manipulating mass publics'. ${ }^{30}$ Checkel's application of persuasive argumentation to an empirical case that examines why agents comply with the norms embedded in regimes and international institutions, concludes that the case study of Ukraine's initial compliance with Council of European norms is 'best explained by a norm-driven dynamic, where persua-

\footnotetext{
24) Risse, “"Let's Argue!”', pp. 20-21.

25) Risse, “"Let's Argue!”, pp. 20-21.

26) Risse, "'Let's Argue!", p. 23.

27) Risse, " "Let's Argue!" ', p. 23.

28) Jeffrey T. Checkel, 'Why Comply? Social Learning and European Identity Change', International Organization, vol. 55, no. 3, summer 2001, pp. 560-564.

29) Checkel, 'Why Comply?', p. 562 [original emphasis].

30) Checkel, 'Why Comply?', p. 562 [original emphasis].
} 
sion and social learning led to interest redefinition' ${ }^{31}$ In both his conceptualizing and application of argumentative persuasion, Checkel emphasizes its non-coercive nature. Yet his reference to 'the absence of overt coercion' leaves open the prospect of covert, implicit or background coercion and politics. By contrast, Risse appears not to consider such a prospect.

The constructivists' ambiguity about coercion, politics and power is problematic. Indeed, self-labelled 'coercive constructivists' Krebs and Jackson challenge their designated 'liberal constructivist' colleagues on the matter, claiming that '[p]ersuasion does not exhaust the ways through which rhetoric might shape political contest'. ${ }^{32}$ Rather than persuasion (understood as non-coercive argumentation) being the process that brings about change, Krebs and Jackson argue that their concept of 'rhetorical coercion' - or 'skilful framing' that leaves opponents 'without access to the rhetorical material needed to craft a socially sustainable rebuttal' and that results in them 'being talked into a corner, compelled to endorse a stance they would otherwise reject' - has more explanatory value. ${ }^{33}$ Their 'model of "rhetorical coercion"' is 'an alternative means of conceptualizing the place of rhetoric in politics' ${ }^{34}$ It replaces persuasion. However, rhetorical coercion is only effective, they claim, when a public audience endorses the particular rhetorical justification given by the actors about their positions or behaviours. ${ }^{35}$ Effective rhetorical justification must be framed to accord with the 'rhetorical commonplaces' that are socially acceptable to the audience. ${ }^{36}$ Given the crucial potential role of the public to punish leaders, Krebs and Jackson are doubtful whether rhetorical coercion will be effective in international politics since, with the possible exception of regional groupings of states, consolidated international audiences are hard to find. ${ }^{37}$ Although the rhetorical coercive model usefully challenges the liberal constructivists' assumption that persuasion - understood as non-coercive argumentation - is explanatory, it also has shortcomings. In particular, Kreb and Jackson's claim that rhetorical coercion is different to persuasion is dependent on a particular conceptualization of persuasion that can be challenged; so, too, their stated conditions under

31) Checkel, 'Why Comply?', p. 577.

32) Krebs and Jackson, 'Twisting Tongues and Twisting Arms', p. 36.

33) Krebs and Jackson, 'Twisting Tongues and Twisting Arms', p. 36.

34) Krebs and Jackson, 'Twisting Tongues and Twisting Arms', p. 36.

35) Krebs and Jackson, 'Twisting Tongues and Twisting Arms', p. 47.

36) Krebs and Jackson, 'Twisting Tongues and Twisting Arms', pp. 45-48. In an empirical illustration of their model, Krebs and Jackson show that the Druze Arabs, in their efforts to overcome second-class citizenship within their homeland Israel, constructed their claims' frame to better their situation by drawing on rhetorical commonplaces deeply rooted in Israel's rhetorical traditions, namely collective military service. Long-standing discrimination by Jewish leaders against the Druze, despite the latter's military service and sacrifices for the Jewish state, became untenable when the Druze 'manoeuvred their Jewish opponents onto a rhetorical playing field on which the Druze could not lose, for no rebuttal would have been acceptable to key audiences, both domestic and international' (p. 52).

37) Krebs and Jackson, 'Twisting Tongues and Twisting Arms', pp. 55-56. 
which rhetorical coercion is effective. These issues will be elaborated upon later, after the present investigation into different literatures' treatment of persuasion.

Like liberal constructivists, scholars in political psychology focus on argumentation as a constituting process of persuasion. Argumentation is studied in several ways, one of which is to link it with framing ${ }^{38}$ to explain changes in citizens' and elites' political opinions and attitudes. The incorporation of framing indicates that it is integral to argumentation and is therefore part of the causal mechanism, or at least, as Gross states, 'numerous studies have shown that the particular frame imposed on an issue or event can shape opinion on related policies'. ${ }^{39}$ Recognition of the close conceptual connections between persuasion, argumentation and framing for explaining outcomes is evident in much of the political psychology literature. Gordon and Miller, for example, argue that 'values are fundamental in framing issues' and 'appealing to values is an effective form of argumentation'. ${ }^{40}$ Recent research also emphasizes the effects of framing on negotiation outcomes. Curseu and Schruijer found that that the 'outcomes depended not on the information [that the group] had [...] but on the way this information is represented'. ${ }^{41}$

The connections between persuasion, argumentation and framing are not only important for understanding how persuasion is constituted but also for appreciating that persuasion can incorporate coercive elements, contrary to most constructivists' conceptualization - that is, if the persuader deliberately constructs a cognitive frame that incorporates an implicit threat that the persuadee may not be able to achieve their interest or that restricts their options, then this is a coercive frame. ${ }^{42}$ The coercive nature of framing and therefore argumentation and persuasion cannot be dismissed. Barnett's study of framing, although not explicitly focused on persuasion, nonetheless raises important questions about the difficulty of establishing the sincerity of the frames that policy-makers use and which determine outcomes. ${ }^{43}$ Furthermore, in practical negotiations it can be difficult to distinguish the boundaries between the subtleties of deliberate

\footnotetext{
38) The vast literature about framing includes many definitions of framing. In essence, a frame is the set of cognitive terms that interlocutors adopt, consciously or sub-consciously, to communicate.

39) Kimberley Gross, 'Framing Persuasive Appeals: Episodic and Thematic Framing, Emotional Responses and Policy Opinion', Political Psychology, vol. 29, no. 2, 2008, p. 170.

40) Ann Gordon and Jerry L. Miller, 'Values and Persuasion during the First Bush-Gore Presidential Debate', Political Communication, vol. 21, 2004, p. 71.

41) Petru Lucian Curseu and Sandra Schruijer, 'The Effects of Framing on Inter-Group Negotiation', Group Decision and Negotiation, vol. 17, no. 4, 2008, p. 357. Confirming the importance of psychological studies of negotiation, Curseu and Schruijer refer to earlier studies that show that 'an accurate understanding of the negotiation process and outcomes in dyads is only possible with a clear understanding of negotiators' mental models', p. 357.

42) See footnote 12 for the definition of coercion that is adopted in this article. Later discussion elaborates upon the article's concept of 'coercive rhetoric' as another aspect of coercive argumentation.

43) Michael Barnett, 'Culture, Strategy and Foreign Policy Change: Israel's Road to Oslo', European Journal of International Relations, vol. 5, no. 1, 1999, pp. 5-36.
} 
psychological manipulation and 'clever' negotiation tactics. Even the common negotiation tactic of giving and taking concessions can involve frames chosen for their psychological effect. Maoz et al. argue that within conflict settlements, framing concessions in terms of exclusion (what will you not concede) versus inclusion (what will you concede?') 'influences people's willingness to make concessions' ${ }^{44}$ The authors argue that the 'inclusion-exclusion effect' shows that 'frames of mind [...] can cause policy-makers and the public to be more or less willing to concede settlements'. ${ }^{45}$ It can hence be assumed that deliberate adoptions of frames that are based on coercion and psychological manipulation as part of argumentation are among the processes of persuasion.

\section{The Conditions of Processes of Persuasion}

Although the reviewed constructivist and political psychology literature certainly focuses on the constituting processes of persuasion, especially the nature of argumentation and framing, the conditions under which these processes have effects on outcomes are also critical aspects of research. Many constructivist scholars studying processes of persuasion examine the scope conditions under which socialization of state agents, especially in European institutions, is possible. ${ }^{46} \mathrm{In}$ a special edition of International Organization, Johnston shows that there is wide variation in the scope conditions that are required for persuasion to occur. ${ }^{47}$ Indeed, there are conditions under which persuasion will not take place. For example, as Johnston indicates, a study by Schimmelfenning 'implies that issues related to identity change, where groups have developed deeply ingrained concepts of self and other, persuasion and communicative action are less likely to work'. ${ }^{48}$ Schimmelfenning's hypothesis that persuasion requires the presence of a 'liberal-minded' interlocutor leads Johnston to make further suggestions about the conditions in this case..$^{49}$ In a broader review of the scope conditions for persuasion, Johnston mentions several other factors, such as the intensity, duration

44) Ifat Maoz, Ilan Yaniv and Naama Ivri, 'Decision Framing and Support for Concessions in the IsraeliPalestinian Conflict', Journal of Peace Research, vol. 44, no. 1, 2007, p. 88.

45) Maoz, Yaniv and Ivri, 'Decision Framing and Support for Concessions in the Israeli-Palestinian Conflict', p. 89.

46) Scope conditions are the particular conditions that are thought to be relevant to processes of persuasion.

47) Johnston, 'Conclusions and Extensions', pp. 1013-1044.

48) Johnston, 'Conclusions and Extensions', p. 1016.

49) Johnston suggests that 'buried beneath the claim that liberal-minded actors are more susceptible to persuasion are at least three possible mechanisms - reason and respect for alternative evidence, the authoritativeness of legal precedent, and consistency'. Johnston's overall summary of the scope conditions for socialization that constructivists offered in the 2005 special edition of International Organization, as well as his own suggestions, were the following: the 'properties of the institutions'; the 'properties of interaction between socializing and socialized agent'; the 'properties of the political systems'; and the 'properties of the issues or objects of contention'. For example, the formal and informal design of the institution that are important conditions for socialization include: the degree of autonomy; norms of 
and quality of exposure to counter-attitudinal messages as critical variables for explaining the success of persuasion, and the noviceness of those being exposed to counter-attitudinal messages. ${ }^{50}$

In an earlier work, Checkel hypotheses that five scope conditions may be needed for argumentative persuasion to be effective. ${ }^{51}$ When assessing these conditions empirically, Checkel found that argumentation and persuasion are effective in European institutions in shaping group dynamics 'only in certain contexts and at specific times. ${ }^{52}$ Empirically, the three conditions that promoted persuasion and deliberation were when uncertainty existed; when early pursuit of the arguing game was assisted by insulation from publicity and overt political pressure; and when several members were highly respected by other group members and renowned for their powers of persuasion. ${ }^{53}$ As these constructivist studies show, there are contextual and temporal limits to the effectiveness of processes of persuasion. Again, however, constructivists assume that the conditions under which socialization takes place are devoid of coercion and politics.

Regarding political psychology literature, examination of the conditions under which processes of persuasion are effective through argument and framing offers many findings. Importantly, in contrast to the conditions outlined in the constructivist literature, this research confirms that argumentation and framing can involve political and coercive conditions. The studies mentioned earlier on framing are cases in point. For example, Gordon and Miller's study of appeals to values as an effective form of argumentation and persuasion, using the first Bush-Gore presidential debate as a case study, finds that 'merely constructing an appeal to values does not guarantee persuasiveness'. ${ }^{54}$ The effectiveness of appeals to values is contingent upon the issue context and the predisposition of the

consensus; trust, reciprocity and compromise; and its organizational characteristics. See Johnston, 'Conclusions and Extensions', pp. 1016-1018.

50) Johnston, 'Conclusions and Extensions', pp. 1023-1025.

51) According to Checkel's research, it is important to identify the conditions that pertain to the persuadee and to the nature of the interaction between the persuadee and persuader. Checkel argues that argumentative persuasion is more likely to be effective when the persuadee is in a novel and uncertain environment and thus cognitively motivated to analyse new information; and argumentative persuasion is more likely when the persuadee has few prior, ingrained beliefs that are inconsistent with the persuader's message. Put differently, agents with few cognitive priors who are novices will be more open to persuasion; argumentative persuasion is more likely to be effective when the persuader is an authoritative member of the in-group to which the persuadee belongs or wants to belong; argumentative persuasion is more likely to be effective when the persuader does not lecture or demand but instead 'acts out principles of serious deliberative argument'; argumentative persuasion is more likely to be effective when the persuader-persuadee interaction in less politicized and more insulated, in-camera settings'. See Jeffrey T. Checkel, " "Going Native” in Europe? Theorizing Social Interactions in European Institutions', Comparative Political Studies, vol. 36, no. 1/2, 2003, p. 213.

52) Checkel, "“Going Native” in Europe?', p. 222.

53) Checkel, "“Going Native” in Europe?', p. 222.

54) Gordon and Miller, 'Values and Persuasion during the First Bush-Gore Presidential Debate', pp. 71 and 78 . 
audience'. ${ }^{55}$ Since the context in this case was the highly politicized Bush-Gore debate and since the audience was the American public, many of whom were supporters of either Bush or Gore, it is evident that the conditions surrounding the processes of persuasion in this case were political. ${ }^{56}$

To summarize, this section has argued that constructivist and political psychology literature provides many useful conceptualizations and research findings on the processes of persuasion and their scope conditions. Criticisms have nonetheless been raised regarding the ambiguity in most constructivist literature about the role of coercion in processes of persuasion and an argument has been mounted that many studies in political psychology understand persuasion in terms of coercive argumentation and framing and emphasize that there are political conditions. The analysis also shows that the three elements that guided the analysis - outcomes, processes and conditions - provide the basis for reference to two models of persuasion: the constructivist and political psychology models. The same elements can be adopted to analyse, construct and compare a diplomatic studies model of persuasion in the following sections.

\section{The Strengths and Shortcomings of Studies of Processes of Persuasion for Diplomatic Studies}

This section examines the relevance - specifically the strengths and shortcomings - of constructivist and political psychology literature on persuasion from a diplomatic studies perspective and, from this analysis, discusses the implications for a model of diplomatic persuasion. The next section will illustrate the value of the diplomatic studies model in comparison to the other models for explaining a diplomatic negotiation that was part of the Solomon Islands peace process in 2003.

From a diplomatic studies perspective, the constructivist and political psychology literature has several strengths, the most significant being the constructivist conceptualization of persuasion in terms of causal micro-processes of argumentation and the political psychology linking of persuasion, argumentation and framing and incorporation of political and coercive dynamics. The

55) Gordon and Miller, 'Values and Persuasion during the First Bush-Gore Presidential Debate', p. 71.

56) In another study on the persuasive power of values-based political messages in domestic politics, Nelson and Garst found that much depends on the recipients' characteristics. Persuasive power depended on the recipients having (i) shared values with the speaker; (ii) shared political party identifications with the speaker; and/or (iii) expectations about values traditionally associated with different political parties (p. 489). The authors' conclusions included that 'The power of political messages derives not only from the values evoked and the party membership claimed by the speaker, but also to some extent on whether these two aspects fit the audience's expectations' (p. 510). These conditions emphasize the political context in which processes of persuasion are embedded. See Thomas E. Nelson and Jennifer Garst, 'Values-Based Political Messages and Persuasion: Relationships among Speaker, Recipient and Evoked Values', Political Psychology, vol. 26, no. 4, 2005, pp. 489-515. 
focus on such processes is under-investigated within diplomatic studies, which tend to explain outcomes either by way of material structures, such as power asymmetries, or intermediate processes such as negotiation, without analysing the causal micro-processes that constitute them. Another major strength of the reviewed studies is the emphasis given to conditions under which processes of persuasion are, or are not, effective.

Nonetheless, from a diplomatic studies perspective, the constructivist and political psychology models have several shortcomings that a diplomatic studies model of persuasion needs to overcome. The political psychology focus on elite and public political opinion, although important (especially to studies of public diplomacy and public affairs), is too narrow given the range of other issues covered in diplomatic studies. The first shortcoming of the constructivist model is that it is based on conceptualizations and frameworks that are ideal-types and that, as its proponents point out, are unlikely to be verified when tested empirically. As Risse points out, 'genuine truth-seeking and ideal speech situations are usually absent during international negotiations. ${ }^{57}$ Although ideal-types are common analytical devices, in this instance the ideal-type is so abstract that its value is questionable. There are few guidelines or criteria for deciding the extent to which the empirical 'approximations' to the abstract notions of genuine truthseeking and ideal speech situations are convincing evidence of the constructivist model's explanatory value. Abstract concepts, such as truth-seeking, still need to be operational concepts that illuminate empirical observations. Because diplomatic studies are largely focused on explanations of empirical phenomena and actual practice, an ideal-type of such an abstraction is problematic. Explanation in diplomatic studies needs a more practical model.

The second shortcoming is that the constructivist model is based on ambiguous assumptions about the role of coercion and politics, both as factors in argumentation and as conditions. Checkel's conceptualization of argumentative persuasion as a process where there is no 'overt coercion', as noted above, implies that coercion may be a covert factor. However, coercion - either as an aspect of argumentation or as conditions - is seen as antithetical to processes of persuasion. Yet we know from political psychology that persuasion can involve coercive argumentation and framing and that the scope conditions can be political in nature. This knowledge raises questions about the constructivist model's conceptualization of persuasion and argumentation. Interestingly, Risse does mention framing in one of his studies but does not consider its coercive and political nature or its role in the outcome. ${ }^{58} \mathrm{He}$ argues that Gorbachev's change of mind

\footnotetext{
57) Thomas Risse, 'Global Governance and Communicative Action', Government and Opposition, vol. 39, no. 2, 2004, pp. 288-313 and p. 303.

58) Risse, “"Let's Argue!”', p. 27.
} 
during the May 1990 negotiations on the German question occurred partly because:

In a decisive move, Bush reframed the issue from a realist discourse into a liberal one. He linked German membership in NATO to the question of self-determination and the principles of the Conference on Security and Cooperation in Europe (CSCE) according to which Germany should have the right to decide for itself which alliance it would join. Gorbachev agreed to this argument right away. ${ }^{59}$

Risse's conclusion - that the outcome was the result of 'arguing out the differences in a true dialogue of mutual persuasion' ${ }^{60}$ — appears to underplay the coercive and political nature of Bush's reframing of Germany's NATO membership. Reframing the issue in terms of liberal principles and CSCE principles of self-determination deliberately pointed to the different governance standards between Russia - recently the lead state of the Soviet Union - and the CSCE. Such a frame was an implicit threat to Russia's vulnerable reputation in the postCold War period and left it with few choices but to agree. These considerations would need to be clarified before concluding that the alleged persuasive processes were absent of coercive framing and that the conditions were apolitical in this particular case.

The role of politics and coercion, not just as processes of persuasion but as conditions, is equally ambiguous in the constructivist model. Although constructivists accept that conditions associated with power dynamics, such as instrumental rationality and bargaining, can be part of the explanation of diplomatic outcomes, the point that such dynamics may well be broader conditions in which the parallel processes of persuasion are taking place is not well investigated. A recent constructivist study goes some way towards recognizing more explicitly that political and coercive conditions can be present at the same time as processes of persuasion. Deitelhoff, using the constructivist model and discourse theory, develops a theoretical model of persuasion to explain a particular law-making outcome, the creation of the International Criminal Court. ${ }^{61}$ Deitelhoff argues that the outcome is explained through 'islands of persuasion', but she also argues that international law-making nonetheless falls short of the deliberative ideal because 'Uneven power distribution, a lack of institutional safeguards, and the fragmented nature of the international system add up to a significant obstacle to discourse and persuasion'. ${ }^{62}$ Although Deitelhoff's argument helpfully reveals some of the political conditions that can surround explanations provided through the constructivist model of persuasion, there is still

\footnotetext{
59) Risse, “"Let's Argue!”, p. 27.

60) Risse, “"Let's Argue!”, p. 23.

61) Nicole Deitelhoff, 'The Discursive Process of Legalization: Charting Islands of Persuasion in the ICC Case', International Organization, vol. 63, no. 1, winter 2009, pp. 33-65.

62) Deitelhoff, 'The Discursive Process of Legalization', p. 61.
} 
the assumption that the 'islands' themselves are immune to the ocean of political and other conditions that she enumerates. The diplomatic studies model would need to investigate critically such an assumption.

These shortcomings do not suggest that the constructivist model cannot explain some diplomatic outcomes; indeed, examples in the constructivist literature make that a distinct possibility. Rather, the criticisms suggest that the model will not explain the majority of diplomatic outcomes, given the broader scope of issues covered in diplomatic studies, the political nature of practical diplomacy and the political conditions in which it operates. Consideration needs to be given to a less restrictive conceptualization of persuasion and its associated conditions: to the possibility that persuasion involves coercive argumentation; that the conditions under which these micro-processes take place may be political and coercive; and that some of these issue-specific conditions may be created through coercive non-verbal signals. As the political psychology literature indicates, since persuasion, argumentation and framing are connected and since framing can be political and coercive in nature, persuasion may well involve politics and forms of coercion.

The 'rhetorical coercion model' offered by self-labelled 'coercive constructivists' Krebs and Jackson does highlight the importance of rhetoric and coercion in explaining political outcomes, as mentioned earlier. However, despite being critical of those they designate as their 'liberal constructivist' colleagues, the authors' model is still based on an important assumption held by liberal constructivists. Both the liberal and coercive constructivists assume that processes of persuasion cannot be conceptualized as being coercive, that persuasion and coercion are antithetical to each other. However, this ignores this article's earlier arguments that framing is integral to persuasion and can be coercive and that persuasion can therefore also be coercive.

This article hence introduces the concept of 'coercive framing'. Coercive framing is evident when the persuader deliberately adopts a cognitive frame that has the intent and/or effect of making the persuadee feel that there is an implicit threat that their non-compliance will have negative consequences for them. The persuadee feels under pressure to change their mind, or to change their position. For example, if the persuader frames an issue in terms of danger, this puts pressure on the persuadee.

Processes of persuasion can involve coercion in another way, such as when an actor points to an interlocutor's rhetorical contradictions. This article hence introduces the concept of 'coercive rhetoric'. This concept is different to Kreb and Jackson's concept of rhetorical coercion, which is an alternative to persuasion and based on the assumption above that persuasion cannot be coercive, an assumption that is peculiar to constructivist thinking and is open to challenge. Coercive rhetoric is evident when the persuader deliberately adopts frames that aim to catch, or have the effect of catching, the persuadee in a contradiction. 
The kinds of contradictions highlighted may be between what the persuadee says and does (between declaratory statements and actions); the standards of the persuadee and those set by particular codes of conduct (such as the Vienna Conventions on diplomacy) or regional and universal standards on an issue (for example, nuclear-free zones, universal human rights standards or non-proliferation); and the negotiating points agreed to by the persuadee and subsequent reneging on those points. Coercive rhetoric, in this sense, is a form of shaming through reference to contradictions, either in private or in front of other negotiators or broader audiences. Unlike Kreb and Jackson's rhetorical coercion, coercive rhetoric does not depend on a domestic audience or a consolidated international audience that can punish those who fail to provide proper justifications. Other audiences $^{63}$ exist and even if they cannot punish, they can undermine an aberrant player's reputation.

Retaining the constructivist model's emphasis on the centrality of persuasion and argumentation as micro-processes of causality, but modifying some conceptualizations and conditions, appears logical for developing a diplomatic studies model of persuasion. Such modifications are justified by political psychology literature, which does not avoid the political nature of social interaction. Moreover, the definition of persuasion in the Oxford Dictionary does not insist that persuasion must be apolitical or non-coercive in either its nature or conditions. Neither does the definition insist that persuasion is a process reserved for explaining only a change of mind, as liberal constructivists insist. Relaxing the constructivist model is hence justified not just by the nature of diplomatic studies, but also by the conceptualization and definitions of persuasion in other sources. ${ }^{64}$

To support the narrative about the necessity of building a diplomatic studies model of processes of persuasion, Table 1 provides three models of persuasion. The diplomatic studies model is both derivative and different when compared to the other two models. ${ }^{65}$ It is different in several ways. First, the processes of

63) For example, in any multilateral negotiations, the delegates are audiences. In any international regime the members are the audience. Although international society is a nebulous term, there are nonetheless identifiable issue-specific audiences: for example, there is an audience that is well aware of a diplomatic culture based on distinctive institutions, values and norms. Even powerful states that transgress this culture are criticized for having double standards — for upholding the culture for other states but contradicting it when it comes to their own actions. See Geoffrey Wiseman, 'Pax Americana: Bumping into Diplomatic Culture', International Studies Perspectives, vol. 6, 2005, pp. 409-430. All of these audiences are capable of shaming, even if punishment is not an option.

64) The Concise Oxford English Dictionary provides the following definition: 'Persuade v. 1. cause to do something through reasoning or argument. 2. cause to believe something. 3. (of a situation or event) provide a sound reason for (someone) to do something'. Point 2 in the definition - 'cause to believe something' - does not stipulate the nature of the 'something': that is, it could be a change of belief or a change in position, or something else. See Soanes and Stevenson, Concise Oxford English Dictionary, p. 1070 .

65) Statements about the nature of diplomatic studies are extensions of the discussion in this article's introduction. 
Table 1: Three Models of Persuasion

\begin{tabular}{|c|c|c|c|}
\hline Element & Constructivist Model & $\begin{array}{c}\text { Political Psychology } \\
\text { Model }\end{array}$ & $\begin{array}{c}\text { Diplomatic Studies } \\
\text { Model }\end{array}$ \\
\hline
\end{tabular}

Outcomes Change of mind Change of elite and regarding norm, interest and preferences, understood as socialization and the internalization of norms

Consensus-only outcomes

Actors

Processes Persuasion, understood as involving causal micro-processes that are apolitical and non-coercive

The processes that constitute persuasion are conceptualized as argumentative rationality and argumentative persuasion public opinion

No insistence on consensus

Mostly domestic elites (officials) and publics Individuals and groups

Persuasion, understood as a micro-process involving psychological factors

Persuasion is conceptualized as argumentation and framing and may involve political and coercive dynamics
Change of mind about an interest or preference, or

Change of position but not change of preference, or

Change of behaviour but not change of preference

Change of foreign elite and public opinion

All changes concern norms and non-norm issues

Consensus and other types of outcomes

State-based officials from foreign ministries and international sections of other government departments, plus INGOs (e.g. UN)

NGOs and civil society actors

Individuals and groups

Persuasion, understood as a micro-causal process conceptualized as argumentation and framing, most likely to involve political and coercive dynamics, in particular (i) coercive framing (which can involve psychological factors, such as framing issues deliberately in terms of danger); and (ii) coercive rhetoric (which involves contradictions, such as between what is said and done) 
Table 1: (cont.)

\begin{tabular}{|c|c|c|c|}
\hline Element & Constructivist Model & $\begin{array}{c}\text { Political Psychology } \\
\text { Model }\end{array}$ & $\begin{array}{c}\text { Diplomatic Studies } \\
\text { Model }\end{array}$ \\
\hline Conditions & $\begin{array}{l}\text { Apolitical and non- } \\
\text { coercive. Note the } \\
\text { scope conditions for } \\
\text { socialization in the text } \\
\text { outlined by Risse, } \\
\text { Johnston and Checkel } \\
\text { Institutions provide } \\
\text { important conditions } \\
\text { for persuasion }\end{array}$ & $\begin{array}{l}\text { Multiple psychological } \\
\text { conditions pertaining } \\
\text { to the processes of } \\
\text { persuasion, } \\
\text { argumentation and } \\
\text { framing (such as } \\
\text { framing with reference } \\
\text { to values, or danger). } \\
\text { Other psychological } \\
\text { conditions pertain to } \\
\text { the attributes of the } \\
\text { messages' } \\
\text { recipients (e.g. degree } \\
\text { of political awareness) } \\
\text { or the message sender } \\
\text { (e.g. trustworthiness) }\end{array}$ & $\begin{array}{l}\text { Multiple conditions at } \\
\text { multiple levels, most likely } \\
\text { to be infused with politics } \\
\text { and to have a coercive } \\
\text { effect, for example (i) } \\
\text { macro-level conditions } \\
\text { such as domestic factors } \\
\text { (e.g. the nature of political } \\
\text { systems, culture or } \\
\text { history), bureaucratic } \\
\text { factors (such as the nature } \\
\text { of the foreign ministry and } \\
\text { its relationships with other } \\
\text { domestic players), or } \\
\text { international and global } \\
\text { factors; (ii) issue-specific } \\
\text { conditions (such as } \\
\text { non-verbal signalling that } \\
\text { can be coercive, } \\
\text { non-coercive or } \\
\text { trust-building, such as the } \\
\text { nature of the negotiating } \\
\text { forum and participants) }\end{array}$ \\
\hline
\end{tabular}

persuasion, although they can be non-coercive, are much more likely to be coercive. Second, political outcomes can be more varied in diplomatic studies, which seek to explain how diplomacy - constituted by processes of communication, negotiation and representation - helps to bring about change and continuities in the interests, preferences and values of diplomatic actors. Furthermore, diplomatic studies do not have an exclusive focus on outcomes that only involve a mind-change or a change in interests and preferences. Diplomatic studies also examine other outcomes, such as outcomes that may include a compromise, or change in position or behaviour, but not necessarily a change of mind. Third, the model includes a wider range of actors than the other two models. Classical diplomacy studies tend to examine foreign ministries, and sometimes particular diplomats. New diplomacy studies tend to focus not just on the foreign ministry but also international sections of other government departments, inter-governmental organizations like the United Nations, institutions and NGOs. Diplomatic studies hence investigate the role of a wide range of actors when explaining 
outcomes, only some of which are the same as those in the other two models. ${ }^{66}$ Fourth, the model allows for a wide variety of conditions and levels under which processes of persuasion take place. In comparison to the conditions of the constructivist model, the diplomatic studies model assumes that the conditions most likely involve politics and can be coercive, including: (i) macro-level conditions generated by the domestic political, social and economic context, both the statecentric international system and the global-interdependent system in which states are the key but not the only political units of action, and the bureaucratic institutional settings, such as the internal nature of the foreign ministry plus its relations with other bureaucracies; and (ii) issue-specific conditions generated by, for example, non-verbal signals created by the interacting parties (such as non-coercive trust-building measures or coercive implied material threats to use physical force), the procedures of the negotiating forum, and the inclusiveness or exclusiveness of negotiation participants. A final point is that the diplomatic studies model is different from the most common model of interaction referred to in diplomatic studies — the bargaining model — which involves processes of give and take or exchanges, often of material assets. ${ }^{67}$

\section{Explaining a Peace Negotiation Outcome}

This case study investigates which of the three models of processes of persuasion can best explain the successful diplomatic outcome of a 2003 peace negotiation between the notorious Solomon Islands' warlord Harold Keke and senior Australian officials from the intervening peacekeeping force, the Regional Assistance Mission Solomon Islands (RAMSI). ${ }^{68}$ The case study frequently features in accounts of regional peacekeeping and the evolving role of different diplomatic actors, such as the foreign ministry, defence ministry and police departments, in negotiating intra-state ceasefires and peace agreements. In this sense the case study is an example of 'new' diplomacy. Keke's surrender is widely acknowledged as a critical event in bringing peace to the Solomon Islands' conflict and, from the Australian government's perspective, regional stability that was necessary for Australia's national security. However, the negotiating processes have not until

66) The reviewed constructivist studies focus mostly on institutions as actors, particularly those in Europe, and give less attention to individual state-based diplomatic actors within these institutions. This is somewhat puzzling since the constructivist focus on discourse and social interaction obviously involves processes of diplomacy and diplomats. This suggests that, even though there is often a silence in constructivist studies about diplomacy and diplomats within institutions, these processes and people are implicit actors in these studies.

67) That said, diplomatic persuasion may be an aspect of convincing parties to accept these material offers.

68) RAMSI forces arrived in the Solomon Islands on 24 July 2003. Some 2,000 soldiers and 300 police were involved. Australia led the intervention, assisted in different ways by New Zealand, Fiji, Samoa, Cook Islands, Kiribati, Tonga, Vanuatu, Papua New Guinea, Naru and the Pacific Islands Forum. 
now been examined in detail, nor have they been analysed in terms of processes of persuasion. ${ }^{69}$

The key questions include: With regard to the outcome, was Keke's surrender to RAMSI a change of mind on his behalf or some other type of outcome, and was there consensus? With regard to the negotiation, were the processes consistent or not consistent with persuasion (that is, argumentation and reasoning), were they non-coercive or coercive processes, and were coercive framing and coercive rhetoric aspects of argumentation? With regard to the conditions of the negotiations, were politics and coercion evident or not? Finally, was the outcome explained by other factors, such as bargaining?

Analysis of the processes and conditions of persuasion involved in the case study illustrates that the diplomatic studies model provides a more convincing explanation of the outcome than do the other two models. With regard to the nature of the outcome - Keke's surrender - the diplomatic studies model allows for different types of outcomes (change of interest, position or behaviour) concerning a range of non-normative and normative issues and it does not insist on consensus. Although Keke's surrender could be partly explained by the constructivist model, since his decision was normative - that is, he rejected further violence to achieve his objectives and declared support for RAMSI's new normative state of law and order in the Solomon Islands - it is difficult to claim that his decision amounted to a change of mind that meant he had internalized the non-violent norm. After surrendering, Keke was imprisoned and could not demonstrate his non-violent norm in practice. He did, however, provide support for RAMSI's efforts to bring in other warlords by encouraging them to disarm - a major feat since although rebel leaders were given amnesty for disarming, there was no amnesty for past criminal offences, of which most leaders and rebels were guilty. Keke's messages to rebel leaders encouraging disarmament were instrumental in making demobilization a peaceful process. RAMSI officials coined 'arrest by appointment' to describe the incident-free disarmament and criminal charges processes that Keke helped to facilitate. But again, is this evidence of internalization of the non-violent norm or Keke's calculation that it was in his interests to cooperate with RAMSI? Interviews with Keke would not provide reliable evidence, since his state of mind deteriorated in prison. Overall, without further evidence, which is now almost impossible to obtain, it cannot be claimed that Keke internalized the non-violent norm or that there was a consensus outcome. It is clear, however, that Keke changed his position - he surrendered. Hence the constructivist model is less useful than the diplomatic studies model for explaining the precise nature of the outcome.

69) Much of the information for this case study was obtained from the author's interviews with a senior member of the Australian delegation. 
With regard to the processes of persuasion adopted in the negotiation, these too are best explained by the diplomatic studies model. Negotiations between Keke and the three senior members of RAMSI, ${ }^{70}$ who had travelled to Keke's remote jungle base in the province of Weathercoast on 13 August 2003, focused on two major issues: RAMSI's argument aimed at convincing Keke to reject violence and adopt the new norms of law and order in the Solomon Islands; and RAMSI's argument aimed at convincing Keke that if he did surrender, RAMSI would take extensive measures to ensure his, and his family's and followers' safety. To make the first point, RAMSI officials employed argumentation and reasoning and framed the Solomon Islands' situation as one in which law and order were the new operating norms to be supported within a short time by a new democratic political system. As one RAMSI official said to Keke, 'the status quo is no longer an option'. RAMSI's objectives were dependent on persuading Keke to surrender. And as RAMSI Special Coordinator Nick Warner later said, 'resolving the Weathercoast conflict was a key objective for RAMSI [.... and that] without pacifying Keke and his followers, we could not hope to restore law and order [in the Solomon Islands]. ${ }^{, 71}$ Until Keke surrendered, other rebel leaders would not join the peace process and would not disarm. Keke's surrender and peace in the Solomon Islands were critical diplomatic objectives for Australia. Officials were concerned about regional stability and Australia's national security following the terrorist attacks on New York and Washington on 11 September 2001, which had reinforced perceptions that fragile states such as the Solomon Islands were vulnerable to a range of disruptive elements, not just terrorists but criminal and money-laundering gangs. But Keke, of course, would be vulnerable if he surrendered, perhaps from RAMSI but certainly from his enemies if they decided not to disarm. The importance of persuading Keke that the situation in the Solomon Islands had changed certainly depended on the delegation's arguing, reasoning and framing skills. Furthermore, RAMSI's framing of the situation in terms of law and order, coupled with the argument that the status quo was no longer an option, can be seen as evidence of coercive framing. Such framing constrained Keke's options and contained an implicit threat that it would not be in Keke's interests to continue with the status quo.

However, in making judgements about the effectiveness of this approach, it is necessary to note that Keke had independent sources of information. His own followers and intelligence networks confirmed that since RAMSI's arrival, law

70) The three senior members of the delegation were: RAMSI Special Coordinator Nick Warner (a diplomat from the Australian Department of Foreign Affairs and Trade); Ben McDevitt, the Commander of RAMSI's Participating Police Force (from the International Deployment Group of the Australian Federal Police); and Lieutenant John Frewen (from the Australian Defence Force).

71) Nick Warner, 'Operation Helpem Fren: Rebuilding the Nation of Solomon Islands', speech to National Security Conference, Sydney, 23 March 2004, p. 3, available online at http://www.ramsi.org/ node/51, accessed 4 June 2009. 
and order in the Solomon Islands was increasing rapidly. Moreover, RAMSI's public messages to the people, framed in terms of the new norms, had widespread support. RAMSI's public messages to rebel leaders and their followers that they could have amnesty to disarm but no amnesty for criminal offences had the support of the majority of people too. These developments confirmed to Keke that his past violent behaviour was not only unacceptable to RAMSI but would be condemned by most Solomon Islanders. There were hence more factors than simply processes of persuasion that explain Keke's agreement that violence was no longer acceptable. Equally important were the conditions surrounding these processes: there was confirmation that the argument being made was in fact correct. Other conditions were also important.

The second issue in the negotiation that helps to explain Keke's surrender was that the Australian delegation reasoned and finally convinced Keke that he would be safe if he did surrender. In part this was a matter of building Keke's trust and in part it depended on what measures RAMSI was willing to take to protect Keke, his family and followers. There was a complex mix of non-coercive and coercive signals that constituted the conditions and that both fostered and undermined trust. On the one hand, the Australian delegation - the 'three big men' of RAMSI - had travelled to Keke's remote jungle base in the Weathercoast completely unarmed: two signals of trust and respect. Ben McDevitt, the Commander of RAMSI's Participating Police Force had also made previous efforts to generate trust by writing to Keke before RAMSI's arrival, requesting the face-to-face meeting. Keke, who was contactable only by a runner, replied via his secretary on Guadalcanal Liberation Front (GLF) letterhead that he would come to a meeting. To generate another signal of trust and respect, the Australian delegation also agreed to meet Keke in front of his chapel's alter, a venue that from Keke's perspective signalled his psychological and spiritual power. ${ }^{72}$ As McDevitt said, giving Keke 'the upper hand' was a signal of respect that inclined him towards some degree of trust of the delegation. On the other hand, although the delegation was unarmed, it simultaneously sent a coercive non-verbal signal that Keke and his followers confronted a potential physical threat. Royal Australian Navy helicopters and warships actively hovered just off shore during the negotiation. Apparently, a member of the delegation 'joked' with Keke that he did not have any helicopters: a joke that surely carried an implied threat. Nonetheless, Keke had the immediate power to harm or kill his interlocutors and his rebel followers made that coercive signal clear to the delegation with a brazen display of their automatic weapons.

\footnotetext{
72) Keke had strong beliefs in the supernatural (as well as Christianity) and his cult following believed that he had extraordinary powers, for example that he could fly above the palm trees. Keke had a psychological hold over his followers' minds, some of his enemies, and some elements of Solomon Islands' society. Keke implicitly used these psychological factors when negotiating with the Australian delegation.
} 
In addition to the offshore threat signal, the delegation added further coercive pressure on Keke with its legal framing that it had a warrant for his arrest on a relatively minor charge of not attending a court hearing about a previous theft of an outboard motor. Such an offence was not likely to be treated harshly by the prosecution, but invoking a legal frame of this nature caught Keke in a contradiction, demonstrating the use of coercive rhetoric to persuade him. Having agreed that law and order was necessary for peace in the Solomon Islands, Keke's refusal to comply with the warrant would have been a contradiction, obvious to Keke, the delegation and his followers. The persuasive power of RAMSI's coercive legal framing and coercive rhetoric based on contradictions can be assessed to some extent by the fact that Keke knew that he could continue in his jungle base and not surrender. He could wage guerrilla warfare against RAMSI's forces - a war that Australian Defence Force (ADF) personnel knew would favour Keke, at least in the short term. Continuing warfare would undermine RAMSI's much publicized objective of bringing law and order to the Solomon Islands.

Clearly, both sides adopted a complex combination of non-coercive and coercive argumentation as well, creating non-coercive and coercive non-verbal signals to constitute the negotiation conditions. Ironically, given this context, the very important condition was that Keke, according to McDevitt, learned to trust the 'three big men' over the course of negotiations. Throughout, all parties showed personal respect for each other, suggesting that positive human relationships played a role in the outcome. These were enhanced by the good faith shown by the delegation in agreeing to the extensive demands that Keke made in the negotiation's next phase, which largely involved bargaining rather than the processes described above. The next three meetings focused on the exact nature of the measures that would make Keke feel secure. RAMSI officials made several offers in response to Keke's demands. Keke would be imprisoned, but not under the control of the Royal Solomon Island Police (RSIP) and not in a common jail but in a facility that RAMSI would build within their Headquarters at Guadalcanal Beach Resort. The facility would be 'proper', as Keke insisted, and would later include a court room for the trial. These measures satisfied Keke's key security concern, to be protected from elements in RSIP who might try to kill him (from most reports this was a reasonable concern). Keke's request that his family stay with him at the facility was not agreed by RAMSI, but the family could visit him regularly. His lieutenants were also to be imprisoned in RAMSI's HQ facility. RAMSI officials responded to Keke's demand that his followers in the Weathercoast be kept safe by promising that a police station would be built in the location. Keke's last demand — to tell his story — was agreed by RAMSI but was later foiled by the court system, which did not allow him enough time to tell his tale in the detail that he no doubt wished. 
In sum, applying the three models to the Solomon Islands' negotiation demonstrates that the diplomatic studies model provides the better explanation of the outcome, for several reasons. First, it demonstrates that the processes involved coercive argumentation comprising coercive framing (that is, the implied threat that continuing the status quo was not an option, as well as the legal warrant for Keke's arrest for a minor offence); and coercive rhetoric (the contradiction if Keke did not comply with the legal warrant for his stealing offence). Second, the specific conditions created to support these processes involved simultaneous non-verbal signals that were both non-coercive (the various trust-building measures such as RAMSI's most senior members' unarmed status) and coercive (Keke's followers' display of weapons and the active presence offshore of the Royal Australian Navy). Third, the general conditions involved various levels of political dynamics (such as the imperative of Keke's surrender for RAMSI's legitimizing objective of bringing law and order to the Solomon Islands' people, against Keke's capacity to stay in the Weathercoast and even to wage a longstanding guerrilla war against RAMSI). Another level of political conditions related to the broader security imperatives behind the Australian-led intervention. Australia's perceived reliance on Keke's surrender was an important factor in bringing peace to the Solomon Islands, underwriting regional stability and Australia's national security, as well as enhancing Australia's reputation in the region as a peace-building actor and a constructive alliance partner to the United States after '9/11' that could look after its 'own backyard'. Finally, and not to be underestimated, was the layer of conditions involving human relations: the respect and finally the trust between the parties that supported all the dynamics.

\section{Conclusion}

This article's original proposition - that investigating the processes of persuasion in diplomatic outcomes is neglected in diplomatic studies to the detriment of explanation - now has more substance following: first, the review of the conceptual achievements of the constructivist and political psychology literature on persuasion and; second, the construction of three models of persuasion, and in particular the model of diplomatic studies. The latter reconceptualizes persuasion. Like the constructivist model, it emphasizes that persuasion involves microcauses of argumentation and reasoning. Unlike the constructivist model, it emphasizes that processes of persuasion can include coercive argumentation for example, coercive framing and coercive rhetoric. And, unlike the constructivist model, it suggests the conditions under which these processes operate also involve political, coercive and power dynamics. The diplomatic studies model is therefore likely to explain the majority of diplomatic outcomes, while the 
constructivist model will explain the small number of outcomes that do not involve coercive argumentation.

Examining the processes of persuasion - argumentation, reasoning and framing — in the Solomon Islands demonstrates that the processes involved coercion and politics and that the conditions under which the negotiation took place involved politics, coercion and power, on both sides. Analysis suggests that the diplomatic studies model captures these dynamics better than the constructivist or political psychology models. The constructivist model - even considering that it is an ideal-type - is far removed from this negotiation's reality in assuming that both the processes of persuasion and the conditions are non-coercive. The political psychology model helps to highlight the politics of framing in argumentation and the importance of psychological factors, such as trust. However, its focus on public opinion is too narrow to explain the outcome of the case study. Obviously, a single case study cannot generate generalizations, but the Solomon Islands' negotiation does demonstrate the value of the diplomatic studies model for exploring diplomatic persuasion.

The case study also shows that further research is needed to clarify many more issues concerned with developing a model for diplomatic studies. For example, revisions of the model would need to illuminate various empirical and conceptual issues, such as:

- the nature of empirical evidence that would confirm the type of outcome that is, how to determine a change of mind or belief, as opposed to a change of position with a behaviour change or a behavioural change without a change of mind;

- the conceptual, operational and empirical variations in argumentation, reasoning and coercion - for example, cultural and historical factors may be important;

- the causal relationship between processes of persuasion and the constructed contextual non-coercive and coercive conditions, such as trust-building signals and threat signals, respectively, of the type that the case study demonstrated;

- the relationship between the processes of persuasion and the conditions, which act as confirmation of the accuracy of argumentation and the frames adopted.

In the meantime, the model helps to raise many questions for research in diplomatic studies. Just three examples are:

- Do different cultures adopt different forms of argumentation, reasoning, framing and coercion and do they construct different types of non-verbal signals? 
- Would comparing different issue-areas (such as economic diplomacy, crisis diplomacy and public diplomacy) provide insights about the processes of persuasion in each area; and what are the conditions that enhance or obstruct diplomatic persuasion in any given issue area?

- Would an examination of the rhetoric, or the nature and logic of argumentation, be a fruitful line of research on diplomatic persuasion?

The model also highlights the importance of developing a curriculum, not just for highlighting the importance of processes of persuasion in explaining diplomatic outcomes but, equally important, developing skill sets for practitioners, such as the construction of frames and non-verbal signals that support the argumentation.

A research agenda that refines the present model of diplomatic studies and then comprehensively investigates the nature of diplomatic persuasion and develops a general concept is waiting in the wings. It is time to fly.

Pauline Kerr is Fellow and Director of Studies at the Asia-Pacific College of Diplomacy (APCD) at the Australian National University. Her research interests include conflict management and diplomacy, peacemaking negotiations in internal conflicts and traditional and human security developments, all in the AsiaPacific region. Her recent publications include: (edited with Stuart Harris and Qin Yaqing) China's New Diplomacy: Tactical or Fundamental Change? (New York: Palgrave Macmillan Press, 2008); 'Human Security and Diplomacy', in Myrium Dunn and Victor Mauer (eds.), The Handbook of Security Studies (London: Routledge, 2010); and 'Human Security', in Alan Collins (ed.), Contemporary Security Studies (Oxford: Oxford University Press, 2010). 